\title{
Assessment of Risk Factors Associated with Bone and Mineral Disease Post-Renal Transplantation: "The Experiences of Two Centers"
}

\author{
Nouf E AL-Otaibi (D' \\ Abdulmalik S Alotaibi' \\ Nataleen A Albekairy ${ }^{2}$ \\ Mohammad S Shawaqfeh (1D) \\ Moawad Alotaibi ${ }^{5}$ \\ Shmeylan Alharbi ${ }^{3,4,6}$ \\ Abdulmalik Alkatheri ${ }^{3,4,6}$ \\ Abdulkreem M Albekairy $3,4,6$ \\ 'Clinical Pharmacy Department, College \\ of Pharmacy, Umm Al Qura University, \\ Makkah, Saudi Arabia; ${ }^{2}$ College of \\ Medicine, King Saud bin Abdulaziz \\ University for Health Sciences, Riyadh, \\ Saudi Arabia; ${ }^{3}$ College of Pharmacy, \\ Pharmacy Practice Department, King \\ Saud bin Abdulaziz University for Health \\ Sciences, Riyadh, Saudi Arabia; \\ ${ }^{4}$ Department of Medical Research, King \\ Abdullah International Medical Research \\ Center (KAIMRC), Riyadh, Saudi Arabia; \\ ${ }^{5}$ Family Medicine Department, Prince \\ Sultan Military Medical City, Riyadh, Saudi \\ Arabia; ${ }^{6}$ Pharmaceutical Care Services \\ Department, King Abdulaziz Medical City, \\ National Guard Health Affairs, Riyadh, \\ Saudi Arabia
}

Introduction: Bone and mineral disease risk following kidney transplantation becomes increasingly a health concern. The objective of this study is to evaluate the possible risk factors associated with bone and mineral disease post-renal transplantation.

Methods: Retrospective observational study was carried out in two kidney transplant centers in Saudi Arabia, King Abdul-Aziz Medical City, Riyadh, and King Abdullah Medical City, Makkah. Patients who are 18 years or older were included. Patients with multiple organ transplantation and pediatric patients were excluded. Eligible kidney transplant patients were included. Baseline relevant laboratory values were recorded from the medical record from the admission and during the following 24 months post-transplantation. Chi-square tests were used to test for the presence of association between categorical variables. An independent $t$-test was also utilized to test for an association.

Results: One hundred ninety-seven kidney transplant patients were included, bone mineral density testing and interpretation for patients before and after transplantation. About $23.4 \%$ had bone mineral density (BMD)tested prior to transplantation. Among those $2 \%$ had osteoporosis, $7.6 \%$ had osteopenia, and $13.7 \%$ had normal BMD. As for post-transplantation imaging, $26.9 \%$ had BMD tested. Among those $11.2 \%$ had osteoporosis, $10.7 \%$ had osteopenia, and $5.1 \%$ had normal BMD. The factors associated with post-transplantation osteoporosis were the history of osteoporosis, the number of rejections, the levels of total calcium, free calcium, and PTH. The factors associated with post-transplantation osteopenia were the history of osteoporosis, the history of osteopenia, the history of osteoarthritis, type of graft, using anti-coagulation, total calcium, free calcium, and phosphate levels. The factors associated with post-transplantation fracture were the history of osteopenia, type of graft, and total calcium levels.

Conclusion: The factors associated with BMD were the history of osteoporosis, osteopenia, and osteoarthritis, number of rejections, levels of total calcium, free calcium, phosphate and $\mathrm{PTH}$, type of graft, and anti-coagulation use.

Keywords: osteoporosis, osteopenia, fracture, risk, kidney, transplantation

\section{Introduction}

Bone and mineral disease (BMD) are the primary cause of morbidity in patients with kidney transplantation (KT), leading to an elevated risk of fractures and consequently increasing the cost of health care, hospitalization, and mortality. ${ }^{1}$ Recipients of KT are especially vulnerable to bone damage considering prior bone-related issues (eg, bone quality or density and mineral metabolism), immunosuppression regimen, and the change in the renal bone metabolism. ${ }^{2}$
Correspondence: Abdulkreem M Albekairy College of Pharmacy, Pharmacy Practice Department, KSAU-HS, Riyadh, I I 48I, Saudi Arabia

Tel +0I I-429500 I; +966505550055

Email bekairy@gmail.com;

bekairya@ngha.med.sa 
Several recent studies indicated that KT recipients have an above-average fracture rate, as they have fewer osteopenia. ${ }^{3}$ In KT, the rate of fractures is higher in the first three years post KT by $34 \%$; after that the general fracture risk is less and is comparable with dialysis patients. ${ }^{4}$ Despite improving mineral metabolism, the fracture risk remains significant even ten years from $\mathrm{KT}^{4}$ The fractures are commonly observed in the hip and foot. ${ }^{5}$ Compared with the general population, KT recipients who suffer from fractures have an increased risk of mortality by $60 \%{ }^{6}$ A recent publication that addressed the bone-vascular axis hypothesis in kidney transplant recipients and fifty four percent developed BMD following transplantation, this is a recent hypothesis that provides explanation of the correlation between transplantation and BMD. $^{7}$

Although the data from the United States Renal Data System (USRDS) indicated that the rate for hip fracture has declined in transplanted patients by $45 \%$ over the years due to less corticosteroids exposure in addition to the improved management of other factors. ${ }^{4}$ However, the risk is still considered elevated relative to general population. In addition, the findings from an analysis in the United Kingdom with 21,769 renal transplant recipients showed that hip fractures are independently associated with a threefold increased risk of mortality. ${ }^{8}$

The underlying mechanism of BMD initially begins in patients with chronic kidney disease (CKD) because of abnormalities in calcium, vitamin $\mathrm{D}$, phosphorus, parathyroid hormone, and fibroblast growth factor $23 .{ }^{1}$ Furthermore, many factors simultaneously elevate the risk of BMD after KT, including the pre-existing CKDrelated renal osteodystrophy and to other factors contributing to bone loss. The BMD characteristics in the posttransplant period include abnormalities such as hypophosphatemia, hypercalcemia, and hyperparathyroidism. ${ }^{9}$ The range of bone loss post KT varies between renal osteodystrophy, osteoporosis, bone fractures, and osteonecrosis. ${ }^{1}$

This study aims to report on the experience of two medical centers in Saudi Arabia in order to evaluate the possible risk factors associated with bone and mineral disease during the first two years' post-renal transplantation.

\section{Primary Objective}

The primary objective of this study is to evaluate the possible risk factors associated with bone and mineral disease post-renal transplantation.

\section{Secondary Objectives}

Secondary objectives to be investigated in this study are to estimate the incidence of osteopenia, osteoporosis, and fractures in such patients.

\section{Operational Definitions}

Osteopenia $=$ BMD between $1 \mathrm{SD}$ and $2.5 \mathrm{SD}$ below the young adult mean (often seen as T-score between -1 and -2.5 ).

Osteoporosis $=\mathrm{BMD}$ at least $2.5 \mathrm{SD}$ below the young adult mean (often seen as T-score of less than -2.5 ).

FRAX: stands for fracture risk assessment tool, a tool that predict the risk of fracture in patients with osteoporosis within the next ten years.

\section{Materials and Methods Study Design and Population}

We performed a retrospective observational study in two kidney transplant centers in Saudi Arabia, King Abdul-Aziz Medical City, Riyadh, and King Abdullah Medical City, Makkah. Patients aged 18 years or older admitted for kidney transplantation in either of these two centers were eligible to participate. Exclusion criteria included patients with multiple organ transplantation and pediatric patients. The study protocol regarding patient data processing and storage for medical research involving human subjects was approved by the Institutional Review Board from both participating centers and conducted in accordance with declarations of Helsinki and Istanbul. Eligible kidney transplant patients were included. As the study is retrospective chart review, the patient consents had been waived but the patient data confidentiality and privacy were maintained. Baseline relevant laboratory values were recorded from the medical record from the admission and during the following 24-months post-transplantation.

The study is retrospective evaluation study, and the electronic medical records were reviewed as deemed necessary. There was information as shown in Table 1 that mentioned the type of the transplanted organ (living vs deceased). According to Saudi Ministry of Health, living organ donation is limited strictly to first degree relatives and this issue is highly regulated. The authors confirm that all kidneys were donated voluntarily with written informed consent, and that this was conducted in accordance with the Declaration of Istanbul.

\section{Statistical Analysis}

Data analysis was performed using IBM Statistical Package for the Social Sciences, SPSS 23rd version 
(SPSS Inc., Chicago, IL). Frequency and percentages were used to display categorical variables in addition to the mean and standard deviation for continuous variables. Chi-square tests were used to test for the presence of association between categorical variables. An independent $t$-test was also utilized to test for an association. The level of significance was set at 0.05 .

\section{Results}

A total of 197 patients were included in the study. Table 1 shows the baseline characteristics of the patients and the reason for transplantation. One hundred and six (53.8\%) participants were males, and $91(46.2 \%)$ were females. Only $15(7.6 \%)$ of the patients were smokers. The mean age of the participants was $45.85+13.96$. The mean BMI of participants was $28.37+6.13$. As for the diagnosis (reason

Table I Baseline Characteristics of Patients and the Reason for Transplantation $(\mathrm{n}=197)$

\begin{tabular}{|l|l|}
\hline Demographical Characteristics & $\mathbf{n}(\%)$ \\
\hline Gender & \\
Male & $106(53.8)$ \\
Female & $91(46.2)$ \\
\hline Age (in Years) & $45.9 \pm 14(18-77)$ \\
\hline Body mass index BMI (kg/m²) & $28.4 \pm 6.13(12-49)$ \\
\hline Smoking Status & \\
Yes & $15(7.6)$ \\
No & $182(92.4)$ \\
\hline Diagnosis (reason of transplant) & \\
Unknown origin & $103(52.3)$ \\
Diabetic nephropathy & $46(23.4)$ \\
Hypertension & $23(11.7)$ \\
Focal Segmental Glomerulosclerosis (FSGS) & $8(4.1)$ \\
Lupus nephritis & $4(2.0)$ \\
Polycystic kidney disease & $4(2.0)$ \\
IgA nephropathy & $3(1.5)$ \\
Alport syndrome & $2(1.0)$ \\
Glomerulonephritis & $2(1.0)$ \\
Reflux Nephropathy & $2(1.0)$ \\
\hline Osteoporosis Risk (FRAX Imaging) & \\
Low & $116(58.9)$ \\
Intermediate & $8(4.1)$ \\
High & $5(2.5)$ \\
Not Done & $68(34.5)$ \\
\hline Hip Fracture Risk (FRAX Imaging) & $119(60.4)$ \\
Low & $10(5.1)$ \\
High & $68(34.5)$ \\
\hline Not Done & \\
\hline
\end{tabular}

for the transplant), the patients were categorized as follows: $103(52.3 \%)$ had an unknown origin, $46(23.4 \%)$ had diabetic nephropathy, 23 (11.7\%) had hypertension, 8 (4.1\%) had focal segmental glomerulosclerosis, $4(2 \%)$ had lupus nephritis, $4(2 \%)$ had polycystic kidney disease, 3 (1.5\%) had IgA nephropathy, 2 (1\%) had Alport syndrome, 2 (1\%) had glomerulonephritis, and 2 (1\%) had reflux nephropathy. Osteoporosis risk as well as hip fracture risk before transplantation are shown in Table 1. The prior transplantation FRAX score for assessment of significant osteoporotic risk showed that $116(58.9 \%)$ had low risk, 8 (4.1\%) had intermediate risk, and $5(2.5 \%)$ had a high risk, while $68(34.5 \%)$ score was not applicable for them. The FRAX score for hip fracture risk prior to transplantation was indicated that 119 $(60.4 \%)$ had low risk and $10(5.1 \%)$ had high risk.

The medical history of patients prior to transplantation revealed that forty-four $(22.3 \%)$ were post-menopause females, 5 (2.5\%) had osteoarthritis, 29 (14.7\%) had osteopenia, 5 (2.5\%) had osteoporosis, and 7 (3.6\%) had a history of fracture.

The post-transplantation medical history of the patients demonstrated that one hundred forty-nine $(75.6 \%)$ had hypertension, 107 (54.3\%) had diabetes, 48 (24.4\%) had osteopenia, 39 (19.8\%) had osteoporosis, $13(6.6 \%)$ had a history of fracture, and $24(12.2 \%)$ had a history of cerebrovascular disease. In addition, the graft type for the patients included in this study were one hundred fortyone $(71.6 \%)$ who had a graft from a living donor, and 56 (28.4\%) had a cadaveric donation.

Bone Mineral Density testing and interpretation for patients before and after transplantation. These findings are shown in Table 2. Only $46(23.4 \%)$ had bone mineral density (BMD) tested prior to transplantation. Among those 4 (2\%) had osteoporosis, 15 (7.6\%) had osteopenia, and $27(13.7 \%)$ had normal BMD. As for post-transplantation imaging, only 53 (26.9\%) had BMD tested. Among those $22(11.2 \%)$ had osteoporosis, 21 (10.7\%) had osteopenia, and $10(5.1 \%)$ had normal BMD.

The medical history of patients prior to transplantation revealed that forty-four $(22.3 \%)$ were post-menopause females, 5 (2.5\%) had osteoarthritis, 29 (14.7\%) had osteopenia, 5 (2.5\%) had osteoporosis, and 7 (3.6\%) had a history of fracture. While post-transplantation medical history of the patients revealed that one hundred fortynine $(75.6 \%)$ had hypertension, 107 (54.3\%) had diabetes, $48(24.4 \%)$ had osteopenia, 39 (19.8\%) had osteoporosis, $13(6.6 \%)$ had a history of fracture, and $24(12.2 \%)$ had a history of cerebrovascular disease. 
Table 2 Bone Mineral Density Findings Prior and Post-Transplantation $(n=197)$

\begin{tabular}{|l|l|l|}
\hline Question & $\mathbf{n}$ & $\%$ \\
\hline $\begin{array}{l}\text { Bone Mineral Density tested } \\
\text { Yes }\end{array}$ & 46 & 23.40 \\
No & 151 & 76.60 \\
\hline $\begin{array}{l}\text { Prior BMD interpretation } \\
\text { Osteoporosis }\end{array}$ & 4 & 2 \\
Osteopenia & 15 & 7.6 \\
Normal & 27 & 13.7 \\
Not done & 151 & 76.6 \\
\hline Findings - 2 Years Post-Transplantation & & \\
\hline Bone Mineral Density tested & & 26.90 \\
Yes & 53 & 73.10 \\
No & 144 & \\
\hline Post-transplantation BMD interpretation & & 11.2 \\
Osteoporosis & 22 & 10.7 \\
Osteopenia & 21 & 5.1 \\
Normal & 10 & 73.1 \\
Not done & 144 & \\
\hline
\end{tabular}

Table 3 displays the biochemical data prior and posttransplantation. For the prior to transplantation biochemical data, the mean total calcium was $2.01+0.40 \mathrm{mmol} / \mathrm{l}$, the mean free calcium was $2.19+0.36 \mathrm{mmol} / \mathrm{l}$, the mean parathyroid hormone (PTH) was $50.01+38.54 \mathrm{pg} / \mathrm{mL}$, and the mean phosphate $\left(\mathrm{PO}_{4}\right)$ was $1.61+0.49 \mathrm{mmol} / \mathrm{l}$. The mean vitamin $\mathrm{D}$ level prior to transplantation was $28.77+16.10 \mathrm{ng} / \mathrm{mL}$. As for the vitamin D level prior to transplantation, 44 (22.3\%) had vitamin D deficiency, 43 (21.8\%) had insufficiency, 53 (26.9\%) had sufficient vitamin D level, and 57 (28.9\%) did not undergo vitamin D investigation prior to transplantation. As for the post-transplantation biochemical data, the mean total calcium was $2.07+0.26 \mathrm{mmol} / \mathrm{l}$, the mean PTH was $24.60+21.31 \mathrm{pg} /$ $\mathrm{mL}$, the mean $\mathrm{PO}_{4}$ was $1.47+2.01 \mathrm{mmol} / \mathrm{l}$, and the mean vitamin D level was $32.40+22.92$. As for the vitamin D level post-transplantation, 46 (23.4\%) had vitamin D deficiency, 37 (18.8\%) had insufficiency, 112 (56.9\%) had sufficient vitamin D level, and 2 (1\%) did not undergo vitamin $\mathrm{D}$ investigation post-transplantation.

The medication history of participants prior to and post-transplantation revealed that the medications prior to

Table 3 Comparison of Mean Between Biochemical Markers Before and After Transplantation

\begin{tabular}{|c|c|c|c|c|}
\hline Variables & & $\mathbf{n}$ & Mean & p-value \\
\hline Calcium total $(\mathrm{mmol} / \mathrm{l})$ & $\begin{array}{l}\text { Before } \\
\text { After }\end{array}$ & $\begin{array}{l}197 \\
197\end{array}$ & $\begin{array}{l}2.01 \pm 0.40 \\
2.07 \pm 0.26\end{array}$ & 0.070 \\
\hline Calcium free $(\mathrm{mmol} / \mathrm{l})$ & $\begin{array}{l}\text { Before } \\
\text { After }\end{array}$ & $\begin{array}{l}184 \\
184\end{array}$ & $\begin{array}{c}2.19 \pm 0.36 \\
5.24 \pm 11.27\end{array}$ & 0.0001 \\
\hline Parathyroid hormone (PTH) (pg/mL) & $\begin{array}{l}\text { Before } \\
\text { After }\end{array}$ & $\begin{array}{l}189 \\
189\end{array}$ & $\begin{array}{l}50.01 \pm 38.54 \\
24.60 \pm 21.31\end{array}$ & 0.0001 \\
\hline Vitamin D (ng/mL) & $\begin{array}{l}\text { Before } \\
\text { After }\end{array}$ & $\begin{array}{l}140 \\
140\end{array}$ & $\begin{array}{l}28.77 \pm 16.10 \\
32.40 \pm 22.92\end{array}$ & 0.117 \\
\hline Phosphate (PO4) (mmol/l) & $\begin{array}{l}\text { Before } \\
\text { After }\end{array}$ & $\begin{array}{l}197 \\
197\end{array}$ & $\begin{array}{l}1.61 \pm 0.49 \\
1.47 \pm 2.01\end{array}$ & 0.339 \\
\hline
\end{tabular}

Note: Bolded p-value $<0.05$ statistically highly significant. 
transplantation were as follows: $87(44.2 \%)$ were taking calcium carbonate, $80(40.6 \%)$ were taking vitamin $\mathrm{D}, 12$ $(6.1 \%)$ were taking prednisolone, $12(6.1 \%)$ were taking anti-epileptic, $7(3.6 \%)$ were taking anti-coagulant warfarin, and $85(43.1 \%)$ were taking PPI. Regarding the anti-epileptic taken by the patients, $1(0.5 \%)$ was taking levetiracetam, $2(1 \%)$ were taking carbamazepine, 5 (2.5\%) were taking pregabalin, $3(1.5 \%)$ were taking phenytoin, and $1(0.5 \%)$ was taking valproic acid. As for the induction therapy, 129 (66.5\%) took antithyroglobulin (ATG), and 68 (34.5\%) took basiliximab. As for the medications taken post-transplantation, $163(82.7 \%)$ were taking steroids, 115 (58.4\%) were taking vitamin D, 8 (4.1\%) were taking bisphosphonate, $97(49.2 \%)$ were taking calcium, 165 (83.8\%) were taking MMF, 8 (4.1\%) were taking anti-epileptic, $30(15.2 \%)$ were taking anti-coagulant, 165 (83.8\%) were taking PPI, and 22 (11.2\%) were taking furosemide. Regarding the anti-epileptic taken by the patients, $1(0.5 \%)$ was taking levetiracetam, $4(2 \%)$ were taking pregabalin, $2(1 \%)$ were taking phenytoin, and $1(0.5 \%)$ was taking valproic acid. The anticoagulants used by the patients were as follows: $11(5.6 \%)$ were taking warfarin, $15(7.6 \%)$ were taking heparin, and 4 (2\%) were taking apixaban.

Figure 1 shows the incidence of osteoporosis, osteopenia, and fracture before and two years after transplantation. There was a statistically significant difference in osteoporosis incidence before and after transplantation $(2.5 \%$ vs $19.8 \%$ ). Similarly, there was a statistically significant difference in osteopenia incidence before and after $(14.7 \%$ vs $24.4 \%$ ). On the other hand, there was no statistically significant difference in fracture incidence before and after transplantation $(3.6 \%$ vs $6.6 \%)$.

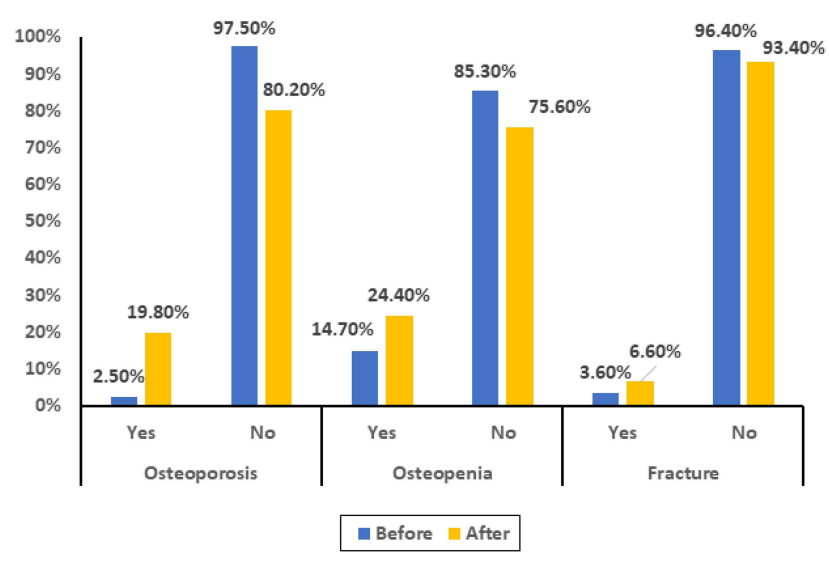

Figure I Distribution of osteoporosis, osteopenia and fracture of before and after transplantation.
Table 4 illustrates the factors associated with posttransplantation osteoporosis. A significant association was observed between the history of osteoporosis prior to transplantation and developing osteoporosis post-transplantation $(p$-value $=0.022)$. A significant association was also observed between the number of rejections and having osteoporosis post-transplantation ( $\mathrm{p}$-value $=0.047)$. A significant correlation was also observed between having post-transplantation osteoporosis and the levels of total calcium $(p$-value $=0.023)$, free calcium $(p$-value $=$ $0.011)$ and PTH (p-value $=0.006)$. Higher means of total calcium and free calcium were seen in those with posttransplantation osteoporosis compared to those who did not have osteoporosis post-transplantation, while lower mean of PTH was observed in those with osteoporosis post-transplantation compared to those without it. All other risk factors were not of statistically significant difference.

Table 5 demonstrates the factors associated with posttransplantation osteopenia. A significant association was observed between the history of osteoporosis prior to transplantation and having osteopenia post-transplantation $(\mathrm{p}$-value $=0.003)$. A significant association was also observed between the history of osteopenia prior to transplantation and having osteopenia post-transplantation ( $p$ value $<0.001)$. A significant association was observed between the history of osteoarthritis prior to transplantation and having osteopenia post-transplantation (p-value $<$ 0.001). A significant association was also seen between type of graft and having osteopenia post-transplantation ( $\mathrm{p}$-value $=0.002)$. A significant association was also seen between using anti-coagulation prior to transplantation and having osteopenia post-transplantation ( $p$-value $=0.003$ ). A significant correlation was also observed between having post-transplantation osteopenia and total calcium ( $p$ value $=0.029)$ and free calcium $(p$-value $=0.026)$, phosphate $(\mathrm{p}$-value $=0.007)$. Higher means of total calcium and free calcium were seen in those with post-transplantation osteopenia than those who did not have osteopenia post-transplantation, while a lower mean of phosphate was observed in those with osteopenia post-transplantation compared to those without it. All other risk factors were not of statistically significant difference.

Table 6 demonstrates the factors associated with posttransplantation fracture. A significant association was observed between the history of osteopenia prior to transplantation and having fractures post-transplantation ( $p$ value $<0.001)$. A significant association was also observed 
Table 4 Factors Associated with Post-Transplantation Osteoporosis

\begin{tabular}{|c|c|c|c|}
\hline \multirow[t]{2}{*}{ Factors } & \multicolumn{2}{|c|}{ Post-Transplantation Osteoporosis } & \multirow[t]{2}{*}{ P-value } \\
\hline & Yes & No & \\
\hline Gender (n, \%) & & & 0.477 \\
\hline Male & $19(17.9 \%)$ & $87(82.1 \%)$ & \\
\hline Female & $20(22 \%)$ & $71(78 \%)$ & \\
\hline Smoking Status (n, \%) & & & $0.17 \mid$ \\
\hline Yes & $5(33.3 \%)$ & $10(66.7 \%)$ & \\
\hline No & $34(18.7 \%)$ & $148(81.3 \%)$ & \\
\hline Diagnosis (reason of transplant) (n, \%) & & & 0.790 \\
\hline Diabetic nephropathy & $9(19.6 \%)$ & 37 (80.4\%) & \\
\hline Focal Segmental Glomerulosclerosis (FSGS) & $2(25 \%)$ & $6(75 \%)$ & \\
\hline Unknown origin & $23(22.3 \%)$ & 80 (77.7\%) & \\
\hline IGA nephropathy & 0 & $3(100 \%)$ & \\
\hline Alport syndrome & 0 & $2(100 \%)$ & \\
\hline Lupus nephritis & 0 & $4(100 \%)$ & \\
\hline Polycystic kidney disease & 0 & $4(100 \%)$ & \\
\hline Glomerulonephritis & 0 & $2(100 \%)$ & \\
\hline Hypertension & $4(17.4 \%)$ & $19(82.6 \%)$ & \\
\hline Reflux Nephropathy & I (50\%) & $\mathrm{I}(50 \%)$ & \\
\hline History of Osteoporosis Prior to Transplantation (n, \%) & & & $0.022^{*}$ \\
\hline Yes & $3(60 \%)$ & $2(40 \%)$ & \\
\hline No & $36(18.8 \%)$ & $156(81.3 \%)$ & \\
\hline History of Osteopenia Prior to Transplantation (n, \%) & & & 0.896 \\
\hline Yes & $6(20.7 \%)$ & $23(79.3 \%)$ & \\
\hline No & $33(19.6 \%)$ & $135(80.4 \%)$ & \\
\hline History of Fracture Prior to Transplantation (n, \%) & & & 0.553 \\
\hline Yes & $2(28.6 \%)$ & $5(71.4 \%)$ & \\
\hline No & $37(19.5 \%)$ & $153(80.5 \%)$ & \\
\hline History of Osteoarthritis Prior to Transplantation (n, \%) & & & 0.991 \\
\hline Yes & $\mathrm{I}(20 \%)$ & $4(80 \%)$ & \\
\hline No & $38(19.8 \%)$ & $154(80.2 \%)$ & \\
\hline Graft Type (n, \%) & & & 0.448 \\
\hline Living & $26(18.4 \%)$ & $115(81.6 \%)$ & \\
\hline Deceased & $13(23.2 \%)$ & $43(76.8 \%)$ & \\
\hline Number of Rejection (n, \%) & & & $0.047^{*}$ \\
\hline 0 & $31(17.7 \%)$ & $144(82.3 \%)$ & \\
\hline I & $8(40 \%)$ & $12(60 \%)$ & \\
\hline 2 & 0 & $2(100 \%)$ & \\
\hline Vitamin D Level (n, \%) & & & 0.335 \\
\hline Deficiency (n, \%) & $7(15.9 \%)$ & $37(84.1 \%)$ & \\
\hline Insufficiency (n, \%) & II (25.6\%) & $32(74.4 \%)$ & \\
\hline Sufficient (n, \%) & $15(28.3 \%)$ & 38 (71.7\%) & \\
\hline Using of Antiepileptic's Prior to Transplantation (n, \%) & & & $0.64 I$ \\
\hline Yes & $3(25 \%)$ & $9(75 \%)$ & \\
\hline No & $36(19.5 \%)$ & $149(80.5 \%)$ & \\
\hline
\end{tabular}

(Continued) 
Table 4 (Continued).

\begin{tabular}{|c|c|c|c|}
\hline \multirow[t]{2}{*}{ Factors } & \multicolumn{2}{|c|}{ Post-Transplantation Osteoporosis } & \multirow[t]{2}{*}{ P-value } \\
\hline & Yes & No & \\
\hline $\begin{array}{l}\text { Using of Anticoagulant Prior to Transplantation (n, \%) } \\
\text { Yes } \\
\text { No }\end{array}$ & $\begin{array}{l}2(28.6 \%) \\
37(19.5 \%)\end{array}$ & $\begin{array}{l}5 \text { (71.4\%) } \\
153(80.5 \%)\end{array}$ & 0.553 \\
\hline $\begin{array}{l}\text { Using of Proton Pump Inhibitors Prior to Transplantation (n, \%) } \\
\text { Yes } \\
\text { No }\end{array}$ & $\begin{array}{l}12(14.1 \%) \\
27(24.1 \%)\end{array}$ & $\begin{array}{l}73(85.9 \%) \\
85(75.9 \%)\end{array}$ & 0.081 \\
\hline $\begin{array}{l}\text { Induction Therapy (n, \%) } \\
\text { Antithymoglobulin (ATG) } \\
\text { Basiliximab }\end{array}$ & $\begin{array}{l}26(20.2 \%) \\
13(19.1 \%)\end{array}$ & $\begin{array}{l}103(79.8 \%) \\
55(80.9 \%)\end{array}$ & 0.862 \\
\hline Body Mass Index (BMI) & $28.49+6.25$ & $28.34+6.12$ & 0.89 \\
\hline Total Calcium - Prior to Transplantation & $2.27+0.29$ & $2.14+0.031$ & $0.023 *$ \\
\hline Free Calcium - Prior to Transplantation & $2.32+0.2$ & $2.15+0.39$ & $0.011 *$ \\
\hline Parathyroid hormone PTH - Prior to Transplantation & $35.19+31.85$ & $54.06+39.15$ & $0.006 *$ \\
\hline Phosphate PO4 - Prior to Transplantation & $1.6+0.45$ & $1.61+0.5$ & 0.96 \\
\hline
\end{tabular}

Note: *Significant at level 0.05 .

between type of graft and having fractures post-transplantation ( $p$-value $=0.001$ ). A higher rate of post-transplantation fracture was found in those with cadaveric graft compared to those who had a graft from living donor. A significant correlation was also observed between having post-transplantation osteopenia and total calcium ( $\mathrm{p}$-value $=0.039$ ). A lower mean of total calcium was found in those with post-transplantation fracture compared to those who did not have fracture post-transplantation. An increase in the fracture incidence was observed post-transplantation in 7 patients (3.6\%) compared to 13 patients $(6.6 \%)$. However, this observation is marked as insignificant with McNamar's test $(p=0.263)$. All other risk factors were not of statistically significant difference.

\section{Discussion}

This study focused on assessing possible risk factors leading to bone and mineral diseases and their incidence within the first two years post kidney transplantation in two tertiary centers in Saudi Arabia. Our retrospective observational study showed a significant association between several risk factors with osteoporosis, osteopenia, and fractures post kidney transplantation. The risk factors correlated significantly with osteoporosis included history of osteoporosis prior to kidney transplantation, the number of graft rejections, and a higher level of total and free calcium with a low PTH level. Moreover, the factors associated with osteopenia risk were prior history to transplantation of osteoporosis, osteopenia, and osteoarthritis, in addition to cadaveric graft type, use of anticoagulation prior to transplantation, higher mean total and free calcium, and lower phosphate level. Additionally, the risk factors associated with post-transplantation fractures were prior history to transplantation of osteopenia, cadaveric graft, and lower total calcium prior to transplantation. As for the incidence of bone and mineral disease post kidney transplantation, our study showed that only 53 patients (26.9\%) had BMD tested post kidney transplantation, of whom $22(11.2 \%)$ had osteoporosis, 21 (10.7\%) had osteopenia, and $10(5.1 \%)$ had normal BMD. ${ }^{9}$

However, when comparing our results to previous studies, Vangala et al described factors affecting osteoporosis risk and promoting bone loss after transplantation, including residual BMD, glucocorticoids, hypomagnesemia, and hypogonadism. ${ }^{10}$ In addition, transplant patients are especially at risk because of the immunosuppression regimen, which could increase the risk of osteoporosis through different mechanisms; most commonly, glucocorticoids can decrease calcium absorption in the intestine and lead to increased calcium loss. They are also known to exert their effect by altering the Receptor Activator of Nuclear Factor- $\mathrm{kB}$ Ligand (RANKL) and osteoprotegerin, thus 
Table 5 Factors Associated with Post-Transplantation Osteopenia

\begin{tabular}{|c|c|c|c|}
\hline \multirow[t]{2}{*}{ Factors } & \multicolumn{2}{|c|}{ Osteopenia } & \multirow[t]{2}{*}{ P-value } \\
\hline & Yes & No & \\
\hline Gender (n, \%) & & & 0.052 \\
\hline Male & $20(18.9 \%)$ & $86(81.1 \%)$ & \\
\hline Female & $28(30.8 \%)$ & $63(69.2 \%)$ & \\
\hline Smoking Status (n, \%) & & & 0.300 \\
\hline Yes & $2(13.3 \%)$ & $13(86.7 \%)$ & \\
\hline No & $46(25.3 \%)$ & $136(74.7 \%)$ & \\
\hline Diagnosis (reason of transplant) (n, \%) & & & 0.660 \\
\hline Diabetic nephropathy & $9(19.6 \%)$ & $37(80.4 \%)$ & \\
\hline Focal Segmental Glomerulosclerosis (FSGS) & $2(25 \%)$ & $6(75 \%)$ & \\
\hline Unknown origin & $30(29.1 \%)$ & $73(70.9 \%)$ & \\
\hline IGA nephropathy & 0 & $3(100 \%)$ & \\
\hline Alport syndrome & $\mathrm{I}(50 \%)$ & $\mathrm{I}(50 \%)$ & \\
\hline Lupus nephritis & I (25\%) & $3(75 \%)$ & \\
\hline Polycystic kidney disease & 0 & $4(100 \%)$ & \\
\hline Glomerulonephritis & I (50\%) & $\mathrm{I}(50 \%)$ & \\
\hline Hypertension & $4(17.4 \%)$ & $19(82.6 \%)$ & \\
\hline Reflux Nephropathy & 0 & $2(100 \%)$ & \\
\hline History of Osteoporosis Prior to Transplantation (n, \%) & & & $0.003 *$ \\
\hline Yes & $4(80 \%)$ & I (20\%) & \\
\hline No & $44(22.9 \%)$ & $148(77.1 \%)$ & \\
\hline History of Osteopenia Prior to Transplantation (n, \%) & & & $<0.00 I^{*}$ \\
\hline Yes & 21 (72.4\%) & $8(27.6 \%)$ & \\
\hline No & $27(16.1 \%)$ & $|4|(83.9 \%)$ & \\
\hline History of Fracture Prior to Transplantation (n, \%) & & & 0.126 \\
\hline Yes & 0 & $7(100 \%)$ & \\
\hline No & $48(25.3 \%)$ & $142(74.7 \%)$ & \\
\hline History of Osteoarthritis Prior to Transplantation (n, \%) & & & $<0.001 *$ \\
\hline Yes & $5(100 \%)$ & 0 & \\
\hline No & $43(22.4 \%)$ & 149 (77.6\%) & \\
\hline Graft Type (n, \%) & & & $0.002 *$ \\
\hline Living & $26(18.4 \%)$ & $115(81.6 \%)$ & \\
\hline Deceased & $22(39.3 \%)$ & $34(60.7 \%)$ & \\
\hline Number of Rejection (n, \%) & & & 0.722 \\
\hline 0 & $43(24.6 \%)$ & $132(75.4 \%)$ & \\
\hline I & $5(25 \%)$ & $15(75 \%)$ & \\
\hline 2 & 0 & $2(100 \%)$ & \\
\hline Vitamin D Level (n, \%) & & & 0.127 \\
\hline Deficiency (n, \%) & $8(18.2 \%)$ & $36(81.8 \%)$ & \\
\hline Insufficiency (n, \%) & $16(37.2 \%)$ & $27(62.8 \%)$ & \\
\hline Sufficient (n, \%) & $17(32.1 \%)$ & $36(67.9 \%)$ & \\
\hline Using of Antiepileptic's Prior to Transplantation ( $\mathrm{n}, \%$ ) & & & 0.958 \\
\hline Yes & $3(25 \%)$ & $9(75 \%)$ & \\
\hline No & $45(24.3 \%)$ & 140 (75.7\%) & \\
\hline
\end{tabular}

(Continued) 
Table 5 (Continued).

\begin{tabular}{|c|c|c|c|}
\hline \multirow[t]{2}{*}{ Factors } & \multicolumn{2}{|l|}{ Osteopenia } & \multirow[t]{2}{*}{ P-value } \\
\hline & Yes & No & \\
\hline $\begin{array}{l}\text { Using of Anticoagulant Prior to Transplantation (n, \%) } \\
\text { Yes } \\
\text { No }\end{array}$ & $\begin{array}{l}5(71.4 \%) \\
43(22.6 \%)\end{array}$ & $\begin{array}{l}2(28.6 \%) \\
147(77.4 \%)\end{array}$ & $0.003 *$ \\
\hline $\begin{array}{l}\text { Using of Proton Pump Inhibitors Prior to Transplantation (n, \%) } \\
\text { Yes } \\
\text { No }\end{array}$ & $\begin{array}{l}21(24.7 \%) \\
27(24.1 \%)\end{array}$ & $\begin{array}{l}64(75.3 \%) \\
85(75.9 \%)\end{array}$ & 0.923 \\
\hline $\begin{array}{l}\text { Induction Therapy (n, \%) } \\
\text { Antithymoglobulin (ATG) } \\
\text { Basiliximab }\end{array}$ & $\begin{array}{l}34(26.4 \%) \\
14(20.6 \%)\end{array}$ & $\begin{array}{l}95(73.6 \%) \\
54(79.4 \%)\end{array}$ & 0.370 \\
\hline Body Mass Index (BMI) & $28.34+6.48$ & $28.37+6.03$ & 0.97 \\
\hline Total Calcium - Prior to Transplantation & $2.25+0.274$ & $2.14+0.32$ & $0.029 *$ \\
\hline Free Calcium - Prior to Transplantation & $2.29+0.22$ & $2.15+0.39$ & $0.026 *$ \\
\hline Parathyroid hormone PTH - Prior to Transplantation & $47.96+49.9$ & $50.92+34.22$ & 0.65 \\
\hline Phosphate PO4 - Prior to Transplantation & $1.44+0.29$ & $1.66+0.53$ & $0.007^{*}$ \\
\hline
\end{tabular}

Note: *Significant at level 0.05 .

decreasing osteoblastogenesis and increasing osteoclast production. ${ }^{10,11}$ Other agents like tacrolimus and sirolimus, were both can cause apoptosis to osteoblasts. ${ }^{12}$ On the other hand, among immunosuppressive agents, mycophenolate seems to have a neutral effect regarding BMD, although evidence is lacking. ${ }^{13}$ Another study in Iraq, included 70 kidney transplant patients followed for six months reported that osteoporosis was seen in $52.9 \%$ of patients, and the risk factors associated with osteoporosis post kidney transplantation included low body mass index, diabetes mellitus, second kidney transplantation, pre-transplant steroid treatment, and Vitamin D deficiency. ${ }^{14} \mathrm{~A}$ systematic review assessing fracture risk post kidney transplantation showed a significant association with older age (increased risk of fractures by $14 \%$ ), female gender ( $42 \%$ increased risk of fractures), diabetes mellitus as a potential risk factor, dialysis pre-transplant (74\% risk increase if fractures), prior fractures, and deceased donor. $^{15,16}$

In our study, the incidence of BMD post kidney transplantation was comparable to that described in previous studies. However, there were some differences regarding the risk factors associated with BMD post kidney transplantation. In our study, the reported factors were divided into osteoporosis, osteopenia, and fractures risk. The first risk factor was having a previous presence of BMD prior to kidney transplantation. Secondly, several graft rejections can be linked to the intensification of immunosuppressive agents during the rejection phase, leading to worsening BMD post kidney transplantation. Thirdly, higher calcium levels in the blood indicate poor absorption of calcium into bones, thus leading to BMD, while having low PTH, which can be anticipated in patients post kidney transplantation, especially during the first six months because of a reduced parathyroid functional gland mass. ${ }^{17}$ Fourthly, the cadaveric graft type was significantly associated with osteopenia and fractures risk. This finding is consistent with two previous studies that compared the effect of cadaveric graft type to living donor graft, where both found a significantly increased fracture risk with the cadaveric graft. ${ }^{18,19}$ Nikkle et al found a $36 \%$ increased risk of fractures in cadaveric graft (HR, 1.36; 95\% CI, 1.24-1.49). ${ }^{19}$ Finally, the use of anticoagulation prior to transplantation has been linked to an increased risk of osteopenia, which could be explained by the effect anticoagulants have on bone metabolism. ${ }^{20}$

To our knowledge, this study is the first to describe both the incidence and risk factors of BMD post kidney transplantation in Saudi Arabia. Moreover, the assessment included osteopenia, osteoporosis, and fracture risk in two tertiary hospitals in central and western regions in Saudi Arabia. However, this study has some limitations, 
Table 6 Factors Associated with Post-Transplantation Fracture

\begin{tabular}{|c|c|c|c|}
\hline \multirow[t]{2}{*}{ Factors } & \multicolumn{2}{|l|}{ Fracture } & \multirow[t]{2}{*}{ P-value } \\
\hline & Yes & No & \\
\hline Gender (n, \%) & & & 0.251 \\
\hline Male & $5(4.7 \%)$ & $101(95.3 \%)$ & \\
\hline Female & $8(8.8 \%)$ & $83(91.2 \%)$ & \\
\hline Smoking Status (n, \%) & & & 0.284 \\
\hline Yes & 0 & $15(100 \%)$ & \\
\hline No & $13(7.1 \%)$ & $169(92.9 \%)$ & \\
\hline Diagnosis (reason of transplant) (n, \%) & & & 0.290 \\
\hline Diabetic nephropathy & 0 & $46(100 \%)$ & \\
\hline Focal Segmental Glomerulosclerosis (FSGS) & $\mathrm{I}(\mathrm{I} 2.5 \%)$ & $7(87.5 \%)$ & \\
\hline Unknown origin & $12(11.7 \%)$ & 91 (88.3\%) & \\
\hline IGA nephropathy & 0 & $3(100 \%)$ & \\
\hline Alport syndrome & 0 & $2(100 \%)$ & \\
\hline Lupus nephritis & 0 & $4(100 \%)$ & \\
\hline Polycystic kidney disease & 0 & $4(100 \%)$ & \\
\hline Glomerulonephritis & 0 & $2(100 \%)$ & \\
\hline Hypertension & 0 & $23(100 \%)$ & \\
\hline Reflux Nephropathy & 0 & $2(100 \%)$ & \\
\hline History of Osteoporosis Prior to Transplantation (n, \%) & & & 0.221 \\
\hline Yes & I (20\%) & $4(80 \%)$ & \\
\hline No & $12(6.3 \%)$ & $180(93.8 \%)$ & \\
\hline History of Osteopenia Prior to Transplantation (n, \%) & & & $<0.00 I^{*}$ \\
\hline Yes & $7(24.1 \%)$ & $22(75.9 \%)$ & \\
\hline No & $6(3.6 \%)$ & $162(96.4 \%)$ & \\
\hline History of Fracture Prior to Transplantation (n, \%) & & & 0.474 \\
\hline Yes & 0 & $7(100 \%)$ & \\
\hline No & $13(6.8 \%)$ & $17(93.2 \%)$ & \\
\hline History of Osteoarthritis Prior to Transplantation (n, \%) & & & 0.547 \\
\hline Yes & 0 & $5(100 \%)$ & \\
\hline No & $13(6.8 \%)$ & $179(93.2 \%)$ & \\
\hline Graft Type (n, \%) & & & $0.00 I^{*}$ \\
\hline Living & $4(2.8 \%)$ & $137(97.2 \%)$ & \\
\hline Deceased & $9(16.1 \%)$ & 47 (83.9\%) & \\
\hline Number of Rejection (n, \%) & & & 0.886 \\
\hline 0 & $12(6.9 \%)$ & $163(93.1 \%)$ & \\
\hline 1 & I (5\%) & $19(95 \%)$ & \\
\hline 2 & 0 & $2(100 \%)$ & \\
\hline Vitamin D Level (n, \%) & & & 0.234 \\
\hline Deficiency (n, \%) & $3(6.8 \%)$ & $4 \mathrm{I}(93.2 \%)$ & \\
\hline Insufficiency (n, \%) & I (2.3\%) & $42(97.7 \%)$ & \\
\hline Sufficient (n, \%) & $6(11.3 \%)$ & 47 (88.7\%) & \\
\hline Using of Antiepileptic's Prior to Transplantation (n, \%) & & & 0.342 \\
\hline Yes & 0 & $12(100 \%)$ & \\
\hline No & $13(7 \%)$ & $172(93 \%)$ & \\
\hline
\end{tabular}

(Continued) 
Table 6 (Continued).

\begin{tabular}{|c|c|c|c|}
\hline \multirow[t]{2}{*}{ Factors } & \multicolumn{2}{|l|}{ Fracture } & \multirow[t]{2}{*}{ P-value } \\
\hline & Yes & No & \\
\hline $\begin{array}{l}\text { Using of Anticoagulant Prior to Transplantation (n, \%) } \\
\text { Yes } \\
\text { No }\end{array}$ & $\begin{array}{l}\text { I (14.3\%) } \\
12(6.3 \%)\end{array}$ & $\begin{array}{l}6(85.7 \%) \\
178(93.7 \%)\end{array}$ & 0.404 \\
\hline $\begin{array}{l}\text { Using of Proton Pump Inhibitors Prior to Transplantation (n, \%) } \\
\text { Yes } \\
\text { No }\end{array}$ & $\begin{array}{l}7(8.2 \%) \\
6(5.4 \%)\end{array}$ & $\begin{array}{l}78 \text { (91.8\%) } \\
106 \text { (94.6\%) }\end{array}$ & 0.420 \\
\hline $\begin{array}{l}\text { Induction Therapy (n, \%) } \\
\text { Antithymoglobulin (ATG) } \\
\text { Basiliximab }\end{array}$ & $\begin{array}{l}\text { I I (8.5\%) } \\
2 \text { (2.9\%) }\end{array}$ & $\begin{array}{l}118 \text { (91.5\%) } \\
66 \text { (97.1\%) }\end{array}$ & 0.133 \\
\hline Body Mass Index (BMI) & $31.48+7.95$ & $28.15+5.95$ & 0.06 \\
\hline Total Calcium - Prior to Transplantation & $2+0.32$ & $2.18+0.31$ & $0.039 *$ \\
\hline Free Calcium - Prior to Transplantation & $2.17+0.27$ & $2.19+0.37$ & 0.88 \\
\hline Parathyroid hormone PTH -Prior to Transplantation & $47.42+25.71$ & $50.41+39.27$ & 0.79 \\
\hline Phosphate PO4 - Prior to Transplantation & $1.61+0.55$ & $1.61+0.49$ & 0.96 \\
\hline
\end{tabular}

Note: *Significant at level 0.05 .

including the retrospective, observational study design, and BMD was not tested for most of the patients included in the study. In addition to the small number of included patients, which may have affected the generalizability of the study results.

\section{Conclusion}

The incidence of BMD post kidney transplantation can be anticipated through several risk factors that were significantly associated with increasing the risk of osteoporosis, osteopenia, and fracture risk post kidney transplantation. According to our finding that the factors associated with BMD were the history of osteoporosis, osteopenia, and osteoarthritis, number of rejections, levels of total calcium, free calcium, phosphate and PTH, type of graft, and anticoagulation use.

Further studies with a larger sample size are warranted to describe strategies to control BMD- associated risk factors and the best treatment options for BMD post kidney transplantation.

\section{Disclosure}

The authors report no conflicts of interest in this work.

\section{References}

1. Bouquegneau A, Salam S, Delanaye P, Eastell R, Khwaja A. Bone disease after kidney transplantation. Clin J Am Soc Nephrol. 2016;11 (7):1282-1296. doi:10.2215/CJN.11371015

2. Schreiber PW, Bischoff-Ferrari HA, Boggian K, et al. Bone metabolism dynamics in the early post-transplant period following kidney and liver transplantation. PLoS One. 2018;13(1):e0191167. doi:10.1371/ journal.pone. 0191167

3. Lip A, Warias A, Shamseddin MK, Thomson B, Wijeratne DT. Effect of bisphosphonates on bone health in adult renal transplant patients: beyond the first year posttransplant - a systematic review and metaanalysis. Cana j Kidney Health Dis. 2019;6:2054358119858014. doi: $10.1177 / 2054358119858014$

4. Sukumaran Nair S, Lenihan CR, Montez-Rath ME, Lowenberg DW, Chertow GM, Winkelmayer WC. Temporal trends in the incidence, treatment and outcomes of hip fracture after first kidney transplantation in the United States. Am J Transplant. 2014;14:943-951. doi:10.1111/ajt.12652

5. Ball AM, Gillen DL, Sherrard D, et al. Risk of hip fracture among dialysis and renal transplant recipients. JAMA. 2002;288:3014-3018. doi:10.1001/jama.288.23.3014

6. Naylor KL, Li AH, Lam NN, Hodsman AB, Jamal SA, Garg AX. Fracture risk in kidney transplant recipients: a systematic review. Transplantation. 2013;95:1461-1470. doi:10.1097/TP.0b013e31828eead8

7. Sotomayor CG, Benjamens S, Gomes-Neto AW, et al. Bone mineral density and aortic calcification: evidence for a bone-vascular axis after kidney transplantation. Transplantation. 2021;105(1):231-239. doi:10.1097/TP.0000000000003226

8. Ferro CJ, Arnold J, Bagnall D, Ray D, Sharif A. Fracture risk and mortality post-kidney transplantation. Clin Transplant. 2015;29:10041012. doi:10.1111/ctr.12621 
9. Vangala C, Pan J, Cotton RT, Ramanathan V. (2018) Mineral and Bone Disorders After Kidney Transplantation. Front Med. 2018;5:211. doi:10.3389/fmed.2018.00211

10. O'Brien CA, Jia D, Plotkin LI, et al. Glucocorticoids act directly on osteoblasts and osteocytes to induce their apoptosis and reduce bone formation and strength. Endocrinology. 2004;145:1835-1841. doi:10.1210/en.2003-0990

11. Kim HJ, Zhao H, Kitaura H, et al. Glucocorticoids suppress bone formation via the osteoclast. J Clin Invest. 2006;116:2152-2160. doi:10.1172/JCI28084

12. Martin-Fernandez M, Rubert M, Montero M, de la Piedra C. Effects of cyclosporine, tacrolimus, and rapamycin on osteoblasts. Transplant Proceed. 2017;49:2219-2224. doi:10.1016/j. transproceed.2017.07.005

13. Sadideen H, Covic A, Goldsmith D. Mineral and bone disorder after renal transplantation: a review. Int Urol Nephrol. 2008;40:171-184. doi:10.1007/s11255-007-9310-y

14. Hameed EO, Sinjari HY. Prevalence and risk factors of osteoporosis in kidney transplant recipients: dual-Energy $\mathrm{x}$-ray absorptiometry scan study. Med J Babylon. 2018;15:267-270. doi:10.4103/MJBL. MJBL_91_18
15. Abbott KC, Oglesby RJ, Hypolite IO, et al. Hospitalizations for fractures after renal transplantation in the United States. Ann Epidemiol. 2001;11:450. doi:10.1016/S1047-2797(01)00226-5

16. Naylor KL, Li AH, Lam NN, Hodsman AB, Jamal SA, Garg AX. Fracture risk in kidney transplant recipients: a systematic review. Transplantation. 2013;95(12):1461-1470.

17. Kalantar-Zadeh K, Molnar MZ, Kovesdy CP, Mucsi I, Bunnapradist $\mathrm{S}$. Management of mineral and bone disorder after kidney transplantation. Curr Opin Nephrol Hypertens. 2012;21(4):389-403. doi:10.1097/MNH.0b013e3283546ee0

18. Nikkel LE, Hollenbeak CS, Fox EJ, et al. Risk of fractures after renal transplantation in the United States. Transplantation. 2009;87:1846. doi:10.1097/TP.0b013e3181a6bbda

19. Nikkel LE, Mohan S, Zhang A, et al. Reduced fracture risk with early corticosteroid withdrawal after kidney transplant. Am J Transplant. 2012;12:649. doi:10.1111/j.1600-6143.2011.03872.x

20. Signorelli SS, Scuto S, Marino E, Giusti M, Xourafa A, Gaudio A. Anticoagulants and Osteoporosis. Int J Mol Sci. 2019;20(21):5275. doi:10.3390/ijms20215275

\section{Publish your work in this journal}

Transplant Research and Risk Management is an international, peer-reviewed open access journal focusing on all aspects of transplantation and risk management to achieve optimal outcomes in the recipient improving survival and quality of life. The manuscript management system is completely online and includes a very quick and fair peer-review system, which is all easy to use. Visit http:// www.dovepress.com/testimonials.php to read real quotes from published authors. 